\title{
Planejamento urbano e o direito à moradia: análise do Residencial Macapaba no município de Macapá-AP
}

\section{Urban planning and the right to housing: analysis of the Macapaba Residential in Macapá-AP}

Naiara Videira dos Santos - Mestra em Sociologia e Antropologia pela Universidade Federal do Pará (UFPA). Atua como socióloga na Secretaria de Estado de Inclusão e Mobilização Social do Amapá. E-mail: nay-videira@hotmail.com.

Edila Arnaud Ferreira Moura - Doutora em Desenvolvimento Socioambiental pelo Núcleo de Altos Estudos Amazônicos da Universidade Federal do Pará (NAEA/UFPA). Professora Titular de Sociologia da Universidade Federal do Pará (UFPA). E-mail: eafmoura@gmail.com.

\section{Resumo}

Este trabalho apresenta uma análise das etapas de planejamento e de implementação de um conjunto habitacional, o Residencial Macapaba, na cidade de Macapá-AP. O Residencial Macapaba, construído em 2014 e 2017, é o maior conjunto habitacional de moradia popular do estado, tendo sido planejado para atender às funções sociais de cidade e com isso garantir o direito à moradia na sua inter-relação com o direito à cidade. $\mathrm{Na}$ realidade demonstra uma deficiência na execução de grande parte do que foi planejado socialmente, impactando negativamente no alcance de uma melhor qualidade de vida para seus moradores. Este estudo analisa o planejamento do empreendimento habitacional e sua perspectiva de funcionalidade de cidade em contraposição à realidade vivenciada pelos novos moradores, refletindo no direito à moradia a essas populações. Como instrumentos para a análise fez-se uso de pesquisa bibliográfica, pesquisa documental e de entrevistas semiestruturadas com gestores e técnicos responsáveis pelo empreendimento habitacional.

\section{Palavras-chave}

Planejamento Urbano. Política Habitacional. Moradia Popular. Macapá.

\begin{abstract}
The present study provides an analysis of the stages of planning and application of a housing complex, Residential Macapaba, in the city of Macapá-AP. The Residential Macapaba, built between 2014 and 2017, is the largest complex of popular housing in the State, planned to attend the social functions of a city and thus ensure the housing right in their interrelationship with the right to a city. In actual fact, proves deficiency in the implementation of much of the socially planned, having a negative impact in achieving a better life quality for its residents. This paper analyzes the planning of housing development and their perspective of city's functionality in opposition to the reality lived by the new inhabitants, reflecting in the housing right to those communities. As a tool to analyze it we used bibliographic research, documental research, and semi-structured interviews with technical managers responsible for the housing enterprise.
\end{abstract}

\section{Keywords}

Planejamento Urbano. Política Habitacional. Moradia Popular. Macapá. 


\section{INTRODUÇÃO}

$\mathrm{Na}$ implementação das políticas públicas no Brasil, nas três esferas de governo, em geral, as fases de planejamento e as fases de execução parecem constituir etapas distintas de um mesmo processo, quando se observa, em sua maioria, a ineficácia e ineficiência dos objetivos e metas propostas, seja nos planos, nos programas ou nos projetos, frente a sua real execução e na forma como são entregues à população (OLIVEIRA, 2006).

No âmbito da política habitacional, correspondendo à garantia de um direito social, faz-se importante que não seja disposta à população apenas parte de obras inacabadas, como a exemplo de inúmeros conjuntos habitacionais, os quais, na maioria das vezes, contam com apenas a casa/apartamento e são desprovidos de equipamentos públicos essenciais. Isso se agrava, quando estes empreendimentos habitacionais estão localizados em áreas totalmente desconectadas da malha urbana, não efetivando, com isso, o direito à moradia e, numa perspectiva mais ampla, o direito à cidade.

Passa-se a constituir, dessa forma, em regra, em vez de exceção, uma execução dos empreendimentos habitacionais desconexos, muita das vezes, com os parâmetros e os prazos estabelecidos nas etapas de planejamento. Dentre os fatores apontados por gerar esse processo, estão a falta de recursos, a própria necessidade de readequações no projeto básico, uma maior responsabilização dos agentes públicos e privados envolvidos e, dentre outros, o que inevitavelmente acaba por comprometer os investimentos na área e o alcance dos objetivos da política pública.

De acordo com Oliveira (2006, p. 274), “a importância do processo se dá principalmente na implementação, pois esta é que vai levar aos resultados das políticas, programas ou projetos".

Neste trabalho, toma-se como objeto de estudo um conjunto habitacional de moradia popular do Programa Minha Casa Minha Vida, o Residencial Macapaba, na cidade de Macapá-AP. Este habitacional de produção estatal teve seu planejamento formulado para atender minimamente às funções sociais de cidade, em relação, principalmente, à moradia, ao transporte e aos serviços públicos (educação, saúde e segurança) e acesso ao trabalho, e, dessa maneira, possibilitar a essas populações a efetivação do direito à moradia na sua interrelação com o direito à cidade.

Trata-se, na atualidade, do maior conjunto habitacional do estado do Amapá, com previsão de moradia para cerca de 31 mil pessoas, e, portanto, corresponde a um empreendimento habitacional com grande impacto para a 
política de habitação na região, pois em termos populacionais sua população chegará a ser maior do que a de 13 municípios dos 16 que compõem o estado.

Dessa forma, objetiva-se apresentar e analisar o planejamento do empreendimento Residencial Macapaba para o atendimento das funções sociais de cidade, e como sua implementação, de fato, no atendimento daquelas, tem refletido na garantia do direito à moradia a essas populações na sua inter-relação com o direito à cidade.

Para desenvolver esta análise, fez-se uso de pesquisa bibliográfica; além de pesquisa documental na Secretaria de Estado de Infraestrutura (SEINF) sobre as etapas de planejamento e de execução do empreendimento, adotando-se como recorte temporal o período de 2011 a 2017; e, também entrevistas semiestruturadas com os gestores (o anterior e o atual) e 5 (cinco) técnicos da SEINF, estes escolhidos por amostragem intencional, visando selecionar os indivíduos que participaram de todas as etapas do planejamento e da execução do habitacional.

\section{PLANEJAMENTO URBANO NAS CIDADES CAPITALISTAS}

O Estado capitalista, no âmbito da configuração do espaço urbano, é responsável pela sua regulação, suas formas de uso e pela formulação das políticas públicas, atuando diretamente ou indiretamente nos mecanismos de reprodução do espaço e do capital. Como alerta Rodrigues (2016, p. 158), o "Estado capitalista é classista, ou seja, não está acima das classes e nem atua para o bem-estar geral, mas age de acordo com os pressupostos do modo de produção capitalista".

Nessa perspectiva, as razões da existência do planejamento do espaço urbano pelo Estado teriam sua gênese em um contexto contraditório, pois visa a acumulação e a reprodução do capital por meio da inclusão de medidas regulatórias e indutoras para o crescimento das cidades. Dessa maneira, estabelecem-se os acordos entre os interesses do setor financeiro, do setor imobiliário e do Estado, muitas vezes, inclusive, financiados com recursos de agências multilaterais e do Banco Mundial (ALVAREZ, 2016).

O chamado urbanismo mercadológico ou estratégico, como conhecido no Brasil e também denominado de "empresarialista" ou "empreendedorista", representa uma forma de planejamento urbano com a adoção de políticas neoliberais, no qual as intervenções urbanísticas são direcionadas para regiões consideradas estratégicas pelo capital, perdendo-se, com isso, a perspectiva de uma regulação do espaço urbano no seu conjunto. Ao mesmo tempo, essas ações interferem na dinâmica de valorização e desvalorização das áreas no caminho 
ou não das intervenções, bem como na relação dos indivíduos e do fluxo de mercadoria e de capital com a cidade (ALVAREZ, 2016).

$\mathrm{Na}$ esteira desse processo, o direito à moradia é afetado por meio das formas de produção e reprodução do espaço urbano, cada vez mais marcados pelo caráter da cidade mercadoria.

O Estado a quem cabe a formulação de políticas públicas, e nesse caso especificamente, a habitacional, contraditoriamente, deve garantir tanto o acesso a esse direito, principalmente à população de baixa renda, quanto à reprodução do capital, para o qual a terra se tornou um dos seus principais recursos. Eis uns dos grandes dilemas do planejamento urbano nas sociedades capitalistas neoliberais.

\subsection{POLÍTICA HABITACIONAL: O DIREITO À MORADIA E O DIREITO À CIDADE}

A ocupação do espaço urbano brasileiro revela um dos aspectos da desigualdade socioespacial na forma como determinados grupos sociais produzem e se apropriam desses espaços, constituindo formas de dominação e de exclusão social. Assim, a desigualdade socioespacial se apresenta como resultante do processo de urbanização capitalista, principalmente no que se refere à diferenciação no uso e na ocupação do espaço urbano, culminando na permanência da desigualdade social e no processo de segregação espacial.

A desigualdade socioespacial exprime formas e conteúdos da apropriação e da propriedade, da mercadoria terra e das edificações, da cidade mercadoria, da exploração e da espoliação da força de trabalho, da acumulação desigual no espaço, da presença e da, aparentemente paradoxal, ausência do Estado capitalista no urbano (RODRIGUES, 2007, p. 73).

Para Rolnik (2015), o Brasil apresenta um modelo desenvolvimentista socialmente perverso dando forma e conteúdo para a constituição de uma das sociedades mais desiguais do mundo, incapaz de atender satisfatoriamente a maioria da população em suas necessidades mais básicas como a moradia, o que na atualidade tem se constituído como um dos principais problemas sociais do país mediante um contexto de urbanização acelerado.

Combinado com uma estrutura de regularização fundiária excludente, o modelo de urbanização estabeleceu as condições de espraiamento de enormes assentamentos autoconstruídos nas franjas urbanas em que as formas ambíguas de segurança da posse e padrões não planejados de uso do solo prevalecem (ROLNIK, 2015, p. 267). 
Cardoso (2008), por sua vez, considera o acesso à moradia como um requisito fundamental para a sobrevivência na cidade. Um paradoxo, quando se analisa que a forma de apropriação e consumo do espaço urbano na sociedade capitalista, na qual a cidade é tida como mercadoria, ocorre de maneira desigual, gerando processo de segregação socioespacial, problemas ambientais, dentre outros.

No Brasil, segundo Vilaça e La Mora (2004), a produção do espaço urbano marcada pela lógica de mercado, em que a moradia constitui um valor de troca, tem gerado um processo de exclusão social e econômico, fazendo com que um grande contingente populacional não tenha acesso à cidade formal.

Desse processo tem resultado a ocupação irregular de terras, principalmente diante da falta de alternativas impostas pelo mercado imobiliário excludente, da ineficácia das políticas públicas urbanas e habitacionais e, ainda, da valorização fundiária e imobiliária que tem sido determinante no modo de consumo e de produção do espaço urbano (VILAÇA; LA MORA, 2004).

Maricato (2003) considera o problema do déficit habitacional como decorrente da subordinação da política pública urbana e habitacional ao capital, no qual os interesses econômicos das grandes corporações direcionam como, quando e onde os investimentos em políticas sociais e redistributivas deverão ser aplicados.

Somam-se a isso, as formas de acesso a essas políticas e a natureza das tipologias habitacionais, muitas das vezes inadequadas às realidades das famílias, mas que trazem maior rentabilidade para o mercado. "Há uma forte disputa pelos investimentos públicos no contexto de uma sociedade profundamente desigual e historicamente marcada pelo privilégio e privatização da esfera pública" (MARICATO, 2003, p. 158).

Para Maricato (2003), a solução perpassaria por reestruturar a política habitacional, garantindo o acesso da população de menor renda às áreas do espaço urbano com melhor qualidade, seja por intermédio da terra urbanizada ou de financiamento, o qual praticamente não foi garantido durante todo o processo de urbanização brasileira a esses segmentos populacionais.

Rodrigues (2007), em análise sobre este tema, ressalta que, com o surgimento da doutrina neoliberal preconizando o Estado mínimo em oposição ao Estado de Bem-Estar Social, com o estímulo às privatizações, à desregulamentação dos direitos sociais e trabalhistas, vivencia-se uma intensificação das desigualdades socioespaciais, pois a coisa pública é transformada em privada e, portanto, fica suscetível às leis do mercado.

A ideia da cidade-mercadoria corresponde justamente à produção da cidade na lógica do sistema capitalista com o aumento do preço da terra e das edificações. 
E, dessa forma, o que passa a interessar em contraposição aos direitos coletivos, numa sociedade sob a égide do capital e de contexto neoliberal, são os direitos individuais seletivos que se concretizam no mercado, entre eles, a moradia.

Castells (1983, p. 209) enfatiza a importância da moradia como fundamental para a existência humana, constituindo "um mundo de signos, um mundo carregado de pulsões e de frustrações, e a composição de seus símbolos é a expressão da inserção social e da evolução psicológica de seus habitantes". Decorre desse fato a sua importância como meio de realização da vida em todos os sentidos.

No entanto, mediante um contexto de capitalismo neoliberal e consequentemente da cidade mercadoria, o acesso às melhores moradias pressupõe a propriedade privada da terra e, portanto, de capital para possuíla. Aos demais, sem recursos financeiros, restam os espaços marcados pela precariedade habitacional e pela insegurança da posse. Dessa maneira, não se trata mais apenas da luta pela moradia, mas também contra a espoliação dos ativos territoriais dos mais pobres, ou seja, do direito de permanecer na cidade.

Nesse parâmetro, a política pública habitacional deve ser formulada partindo do pressuposto da inter-relação do direito à moradia com o direito à cidade, pois, a efetivação da segurança da moradia se faz também por meio do acesso a um conjunto de direitos sociais, muitos inclusive, preconizados como funções sociais da cidade. E, com isso permitir a esses indivíduos ou grupos a realização plena do direito à vida urbana, por meio do acesso à cidade com todos os seus recursos e, dessa forma, combater/minimizar os processos de exclusão socioespacial, principalmente para a população de baixa renda.

As lutas pelo "direito à cidade", que ganham lugar na metrópole, se realizam como direito à vida urbana, revalorizando o sentido da produção do espaço urbano como criação do homem e colocando fim às alienações vividas; e, logo, como crítica radical do cotidiano (CARLOS, 2017, p. 56).

Rodrigues (2007) corrobora com a ideia de que o direito à cidade se constitui também como a luta para acessar essa cidade, portanto, "o direito à cidade é a luta pelo direito à vida" (RODRIGUES, 2007, p. 87).

Lefebvre (2001), o autor que cunhou o termo "o direito à cidade", também ressalta sua correlação como a conquista de direitos por meio da prática social dos agentes, entre eles, à educação, à habitação, ao trabalho digno e à vida. E, portanto, o direito à cidade "só pode ser formulado como direito à vida urbana, transformada, renovada” (LEFEBVRE, 2001, p. 117). 
Nessa perspectiva, pensar o direito à cidade constitui-se elemento fundamental como base de construção de uma sociedade fundada em novas maneiras de produzir o espaço urbano, revelando uma urgência de mudança da vida e nas configurações socioespaciais das cidades.

\subsection{CONFIGURAÇÃO DAS POLÍTICAS HABITACIONAIS NO MUNICÍPIO DE MACAPÁ}

No município de Macapá, os investimentos em habitação iniciam-se na década de 1980, ainda no governo do território federal do Amapá, com a edificação de conjuntos habitacionais direcionados exclusivamente aos trabalhadores do seu quadro administrativo. A Caixa Econômica Federal (CEF) era a responsável pelas linhas de financiamento.

Os primeiros conjuntos habitacionais construídos foram: o Conjunto Cabralzinho, localizado na zona oeste da cidade, na rodovia Duca Serra; seguido do conjunto Laurindo Banha, situado no bairro do Congós; e, posteriormente, o Conjunto Boné Azul, na Zona Norte, na rodovia BR-210. Eram localizados em áreas consideradas como bairros dormitórios da cidade, pois não contavam com infraestrutura adequada, nem equipamentos públicos e áreas comerciais. Posteriormente, surgiram mais dois conjuntos habitacionais: o San Marino e o Ego (GARCIA, 2014).

Em 1988, a prefeitura municipal realizou a abertura do loteamento Jardim Felicidade, na Zona Norte da capital, disponibilizando mais de 2 mil lotes de terra e inaugurando uma política de doação de lotes sem infraestrutura, mas que beneficiou, segundo o IBGE (2000), uma média de 15 a 20 mil famílias no município. Destaca-se ainda que, por meio do financiamento do governo federal e por intermédio da Empresa Municipal de Urbanização de Macapá (EMDESUR), foram construídas nesse período entre 1000 e 1500 unidades habitacionais (TOSTES; LUZ, 2014).

Nesse mesmo momento, devido ao rápido crescimento populacional e frente ao já expressivo déficit habitacional no município de Macapá, inicia-se um movimento de ocupação gradativa das áreas de ressaca. As localidades mais atingidas são a ressaca do Chico Dias, a ressaca do Congós e nas proximidades do Canal do Jandiá, resultando num processo gradual de aterramento dessas áreas e se configurando como um reflexo negativo desse contexto (TOSTES; LUZ, 2014).

O problema de habitação em áreas irregulares e precárias em Macapá agravase ainda mais com a instalação do ciclo político eleitoral com a transformação 
do território em estado em 1988, havendo o aumento do processo migratório e a invasão em várias partes da cidade.

Entre as principais áreas invadidas estavam as ressacas na região do bairro do Araxá e Beirol e também nas áreas próximas ao Conjunto Cabralzinho e à Lagoa dos Índios. É ainda resultante desse contexto, o surgimento de diversos bairros, muitos dos quais, até hoje, não possuem regularização fundiária, constituindo-se como um obstáculo para obtenção de financiamentos públicos (TOSTES, 2012).

Na segunda metade da década de 1990, começam a surgir os loteamentos promovidos pelo Estado e pela Prefeitura Municipal de Macapá. Trata-se de lotes que apresentavam a estrutura de aberturas de ruas, as delimitações dos lotes e dos quarteirões e a colocação de postes para a instalação de energia elétrica, mas sem a previsão para a implantação de serviços de infraestrutura, como o de saneamento básico. Surgiram, assim, os loteamentos Infraero I e II, Buriti e Renascer, na Zona Norte da cidade, e os loteamentos Açaí e Marabaixo I, II e III, na chamada Zona Oeste do município (GARCIA, 2014).

Paralelamente ao surgimento dos loteamentos públicos, Garcia (2014) destaca a edificação de loteamentos privados por diversas áreas da cidade de Macapá, como na Lagoa dos Índios, no Muca, na Fazendinha e no Pantanal. Em 1999, iniciou-se a construção do primeiro edifício verticalizado da cidade, o Tumalina Residence, com mais de dez andares, cuja edificação - paralisada por mais de 10 anos- só foi possível com a alteração no plano diretor de 2004, por meio da Lei nº 077/2011.

Em 2010, a Prefeitura Municipal de Macapá fez a entrega dos apartamentos do conjunto habitacional de moradia popular, o Complexo Residencial Mucajá, resultante do Programa de Aceleração do Crescimento (PAC). Este foi o primeiro empreendimento no município com recursos federais, vindo beneficiar 592 famílias em situação de vulnerabilidade e risco social. Mas, infelizmente, no conjunto, hoje, são visíveis tantos problemas de segurança quanto sociais, o que tem agravado ainda mais a situação de vulnerabilidade dessas famílias.

Com recursos do Programa Minha Casa Minha Vida I (PMCMV I) do governo federal, criado em 2009, e, com contrapartida da Prefeitura Municipal de Macapá, edificou-se o conjunto residencial de moradia popular Mestre Oscar Santos, em 2012, com a entrega de 528 habitações populares. Com recursos do PMCMV II são resultantes o Residencial São José, finalizado em 2016, com cerca de 1.440 apartamentos e o Residencial Jardim Açucena, com a produção de 1.500 moradias. 
Da construção de habitações com recursos do PMCMV II e com contrapartida do Governo do Estado do Amapá é resultante o Conjunto Habitacional Residencial Macapaba, finalizado em 2017, com a entrega de 4.366 moradias. Há ainda recursos do Programa de Aceleração do Crescimento (PAC 2) e do Fundo Nacional de Habitação de Interesse Social (FNHIS) para a construção do Conjunto Habitacional Congós, visando a edificação de 397 unidades e o Conjunto Habitacional Aturiá, com 512 apartamentos, ambos na zona sul da cidade, mas cujas obras estão paralisadas desde 2011.

Paralelamente aos investimentos públicos, vêm sendo crescentes, no município de Macapá, os investimentos privados em habitação, pois, entre 2010 e 2015, foram construídos 28 empreendimentos privados (SILVA, 2017), atendendo ao segmento populacional de classe média e alta que pode pagar pelos altos financiamentos.

Não há dúvida de que, nos últimos 10 anos, tem ocorrido um maior financiamento para a política habitação no município, principalmente por meio do governo federal. No entanto, esses investimentos ainda se apresentam inexpressivos diante do alto déficit habitacional de Macapá. Segundo a Fundação João Pinheiro (FJP, 2016), esse número chegava a um total de 21.104 domicílios, sendo 20.540 em áreas urbanas e 564 em áreas rurais, um índice bastante elevado quando comparado ao déficit total no Estado que, nesse mesmo período, correspondia a 35.419 unidades.

A seguir, apresenta-se em maiores detalhes o conjunto habitacional Residencial Macapaba como parte dessa política pública que vem sendo desenvolvida no município de Macapá no âmbito do PMCMV, destacando suas especificidades quanto ao seu planejamento e implementação na garantia do direito à moradia e na sua inter-relação com o direito à cidade.

\section{CONJUNTO HABITACIONAL "RESIDENCIAL MACAPABA" E SEU PROJETO DE CIDADE}

O Conjunto Habitacional Residencial Macapaba faz parte do Programa Minha Casa Minha Vida II (PMCMV II) do governo federal com a contrapartida do Governo do Estado do Amapá por meio do Programa de Obras e Ações para Mudar o Amapá (PROAMAPÁ), com um total de investimentos de mais 200 milhões de reais com recursos do Fundo de Arrendamento Residencial (FAR) (SEINF, 2012).

O empreendimento, à época de sua construção, chegou a ser considerado como o maior programa habitacional da América Latina, pois tinha como meta 
a edificação de 5.166 unidades habitacionais, visando atender além da Faixa I (renda de até $\mathrm{R} \$ 1.600,00)$, também um segmento populacional específico, como o funcionalismo público.

Com a finalização das obras em 2017, foram concluídas um total de 4.366 unidades habitacionais, destinadas exclusivamente à população inserida na faixa I do programa, as quais constituem o foco do déficit habitacional no estado.

Foram necessários 5 anos (2012-2017) para a conclusão do empreendimento que se dividiu em duas etapas: a primeira, com a edificação de 2.148 unidades habitacionais, sendo 1.984 apartamentos e 164 casas, denominado Macapaba Fase I, no ano de 2014; e, a segunda etapa, correspondendo à produção de mais 2.218 unidades, distribuídas em 2.048 apartamentos e 170 casas térreas, o Macapaba - Fase II, finalizada em 2017.

Fazendo uma comparação da população a residir no Residencial Macapaba com os municípios do Amapá, é possível ter uma dimensão da grandiosidade desse empreendimento habitacional e do contraste com a realidade do estado, pois seu contingente populacional corresponde a um número maior do que a maioria dos municípios amapaenses, ficando somente atrás de Macapá, a capital, e de Santana e Laranjal do Jarí, que são os três maiores em termos populacionais.

Diante da magnitude do empreendimento e ainda de fatores como a localização do conjunto em uma área distante do centro da cidade e carente em serviços e equipamentos públicos, fazia-se necessário o desenvolvimento de um projeto habitacional que pudesse abranger as condições para o alcance do direito à moradia na sua concepção mais ampla com o alcance de qualidade de vida urbana, e, portanto, a sua imbricação com o próprio direito à cidade.

Nesse aspecto, para o Residencial Macapaba configurou-se um projeto habitacional para atender as funções sociais de uma cidade, principalmente, em relação à educação, à saúde, à segurança, ao transporte e acesso ao trabalho, além da moradia. Porém, quando se analisam as condições vivenciadas cotidianamente pelos moradores, revelam-se duas realidades bastante distintas entre o que foi planejado e que foi implementado no conjunto até o presente momento.

\subsection{CARACTERIZAÇÃO DO CONJUNTO HABITACIONAL "RESIDEN- CIAL MACAPABA": FORMULAÇÃO E PLANEJAMENTO DO EMPREENDIMENTO}

O conjunto habitacional Residencial Macapaba está localizado às margens do km final da BR-210, que liga Macapá aos municípios setentrionais do estado, situando-se em uma área em descontinuidade com a malha urbana. Está localizado no Lote n⿳ำ 103V, gleba AD-04, local anteriormente denominado 
de Retiro dos Atalhos, no bairro Brasil Novo, na Zona Norte de Macapá. E está circunscrito por apenas três bairros, o Açaí, o Infraero I e II e pelo Loteamento Morada das Palmeiras.

Figura 1 - Macrozoneamento urbano da cidade de Macapá, com identificação do bairro Brasil Novo e do Residencial Macapaba

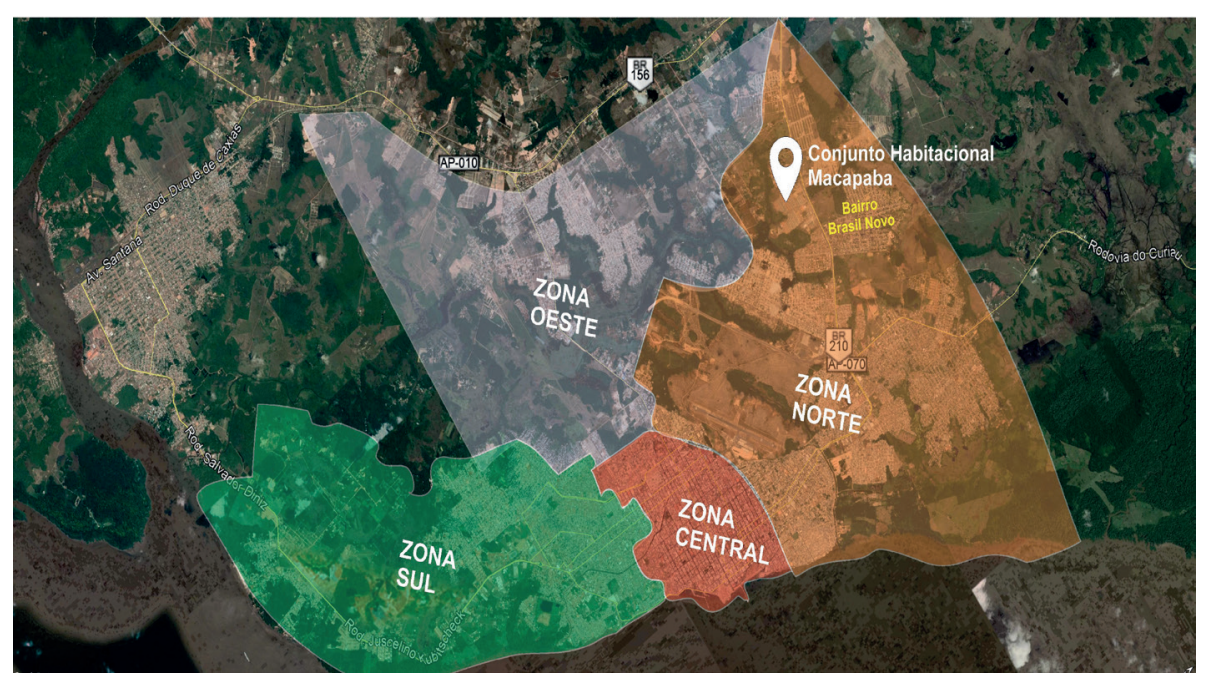

Fonte: Google Earth, 2018. Elaboração: Karina Nymara, 2018.

O terreno do conjunto foi adquirido pelo Governo do Estado do Amapá e depois repassado para o Fundo de Arrendamento Residencial (FAR) com uma dimensão de 1.039.353,00 m pelo valor venal de $\mathrm{R} \$ 6.0000 .000,00$ (seis milhões de reais) no ano de 2011, de propriedade de Altair Pereira Imóveis.

De acordo com informações obtidas na SEINF, órgão estadual responsável pela coordenação do projeto habitacional, na definição da localização do conjunto utilizaram-se dados do Instituto de Meio Ambiente do Amapá (IMAP) sobre as áreas com potencial para loteamentos. E, após diversos estudos, na área conhecida como Retiro dos Atalhos, foram identificadas as condições adequadas para a execução de um empreendimento da magnitude que se propunha o Residencial Macapaba.

De acordo com o técnico da coordenadoria de habitação da SEINF e participante de todo o processo de elaboração e sistematização das etapas de planejamento do empreendimento, a escolha pela localização corresponde a um modelo de planejamento urbano com enfoque na descentralização da cidade promovendo a ocupação e o desenvolvimento de espaços mais distantes dos centros urbanos. No entanto, segundo Tostes e Luz: 
O exemplo do Conjunto Macapaba é apenas um fragmento da análise sobre como ocorrem os projetos financiados pelo próprio governo federal com profundas contradições e a principal é a que coloca em segundo plano, a execução do planejamento urbano (TOSTES; LUZ, 2014, p. 7).

Nesse aspecto, ressalta-se a distância do conjunto em relação ao centro da cidade, em média de 10,1 km, requerendo, dessa maneira, um longo tempo de deslocamento, principalmente, com a utilização de transporte coletivo local o qual é extremamente deficitário em todo o município de Macapá.

A construção das unidades habitacionais do conjunto ficou a cargo da empresa Direcional Empreendimento, contratada por meio de processo de edital de chamamento público, selecionada por apresentar as condições técnicas e financeiras exigidas pelo certame.

A distribuição do espaço no empreendimento habitacional dá-se da seguinte forma: para as unidades habitacionais um total de $221.009,97 \mathrm{~m}^{2}, 9,06 \%$; para as áreas comerciais $35.462,95 \mathrm{~m}^{2}, 3,41 \%$; para as áreas verdes um total de $54.781,82 \mathrm{~m}^{2}, 5,27 \%$; para as áreas institucionais $457.427,4 \mathrm{~m}^{2}, 44,01 \%$; para a estação de tratamento de água e esgoto $118.216,86 \mathrm{~m}^{2}, 11,37 \%$; e para o sistema viário e estacionamentos $108.127,38 \mathrm{~m}^{2}$, equivalente a $10,40 \%$ da área total.

$\mathrm{Na}$ análise das distribuições das áreas/setores do Residencial Macapaba, nota-se que as áreas destinadas para a implantação de equipamentos públicos equivalem a 44,01\% da área total do empreendimento, correspondendo à maior parte da ocupação do terreno. São espaços destinados para a construção de 5 (cinco) escolas, 1 (um) posto de saúde, 1 (um) centro integrado de bombeiro e militar, 1 (um) terminal de ônibus, além de área de lazer (Figura 2).

A destinação desses espaços demonstra de fato uma proposta para atendimento das funções sociais da cidade a que se propõe este empreendimento no atendimento dos direitos sociais como educação, saúde, segurança e transporte, ampliando, dessa forma, a noção do direito à moradia vinculado com o direito à cidade.

A implantação de serviço de infraestrutura de abastecimento de água e de tratamento de esgoto em todo o habitacional também se constitui um dado importante, pois afeta diretamente a qualidade de vida das populações, principalmente em relação à saúde, que faz parte do rol das funções sociais da cidade. Esse dado se torna mais importante quando se constata que no município de Macapá somente 5,78\% da população possui o serviço de esgotamento sanitário e apenas 36,92\% é atendida com abastecimento de água (BRASIL, 2016a).

Outro ponto importante a se destacar é o percentual de 3,41\% destinado para a implantação setores comerciais no empreendimento, visando possibilitar 
o dinamismo econômico local, fomentando, com isso, a geração de empregos (Figura 2). O acesso ao trabalho, também considerado, função social da cidade, mediante o contexto da sociedade capitalista, e do ideal da cidade mercadoria, torna-se fundamental para a sobrevivência dos indivíduos tanto para obtenção quanto para a manutenção da moradia, e de uma forma geral, propriamente dita, para viver nas cidades.

Figura 2 - Mapa de implantação do Residencial Macapaba por setores institucionais e comerciais

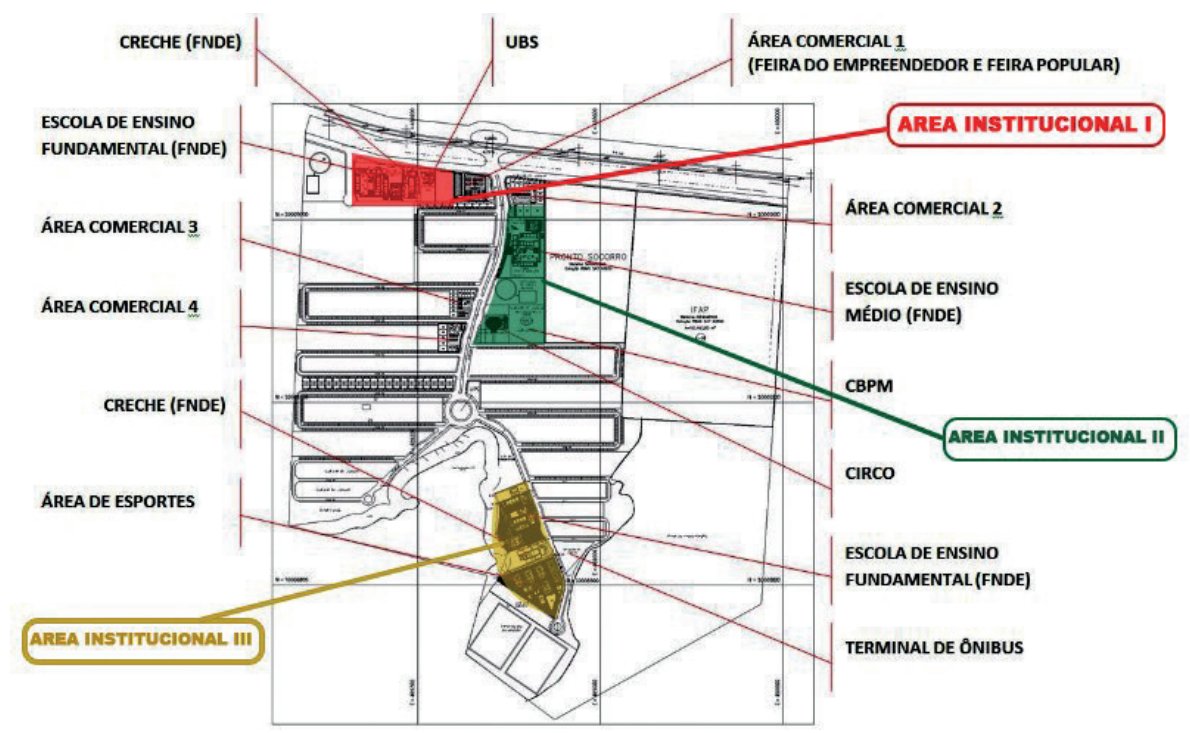

Fonte: SEINF (2016), com adaptações das autoras.

A distribuição e o quantitativo dos equipamentos públicos e comerciais do Residencial Macapaba foram planejados de acordo com informações da SEINF (2012) em estudos de impacto de vizinhança e social, necessários para atender aos novos residentes do habitacional e das áreas adjacentes, devido à carência desses serviços no conjunto e nas localidades ao entorno, conforme demonstra a Figura 3.

Dessa maneira, a forma como foi concebido o projeto habitacional do Residencial Macapaba demonstra um planejamento a partir de uma perspectiva para o atendimento das funções sociais de cidade com vistas a possibilitar aos novos moradores o atendimento de demandas sociais, econômicas e de urbanidade, tais como o acesso aos serviços de infraestrutura, como tratamento de água e esgotamento sanitário, vias com asfaltamento, serviços e equipamentos públicos essenciais, áreas de convívio social e comerciais. 
Figura 3 - Equipamentos públicos no Residencial Macapaba e no seu entorno

\section{CONJUNTO HABITACIONAL MACAPABA - EQUIPAMENTOS PÚBLICOS}

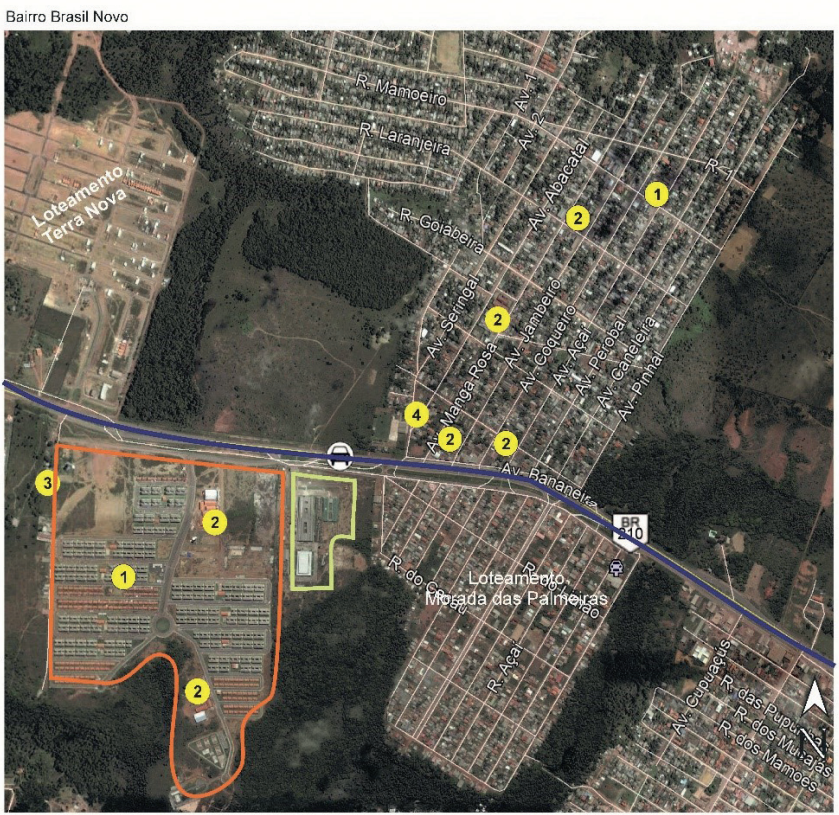

\section{LEGENDA}

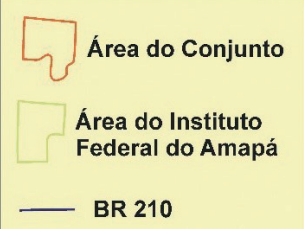

1 - UNIDADE DE POLICIAMENTO COMUNITÁRIO

2 - ESCOLAS

3 - IGREJAS

4 - UNIDADE BÁSICA

DE SAÚDE

DADOS GERAIS

SISTEMA DE PROJEÇÃO SIRGAS 2000

FONTE DA IMAGEM DIGITAL GLOBE
GOOGLE EARTH

Fonte: Google Earth, 2018. Elaboração: Karina Nymara, 2018.

No entanto, entre o planejado e o executado no empreendimento do Residencial Macapaba, para atender de fato essas funções sociais de cidade, existe um cenário com muitos problemas e deficiências, principalmente na oferta de serviços e de equipamentos públicos, fatores que têm dificultado a efetivação do direito à moradia, bem como do direito à cidade. De acordo com Sposati (2001, p. 37), "é pela relação com os serviços públicos que o morador acessa as condições de qualidade de vida urbana".

\section{2 "RESIDENCIAL MACAPABA” HOJE}

Neste item, aborda-se as condições atuais do Residencial Macapaba em relação ao atendimento das funções sociais da cidade, fulcro do direito à cidade, sobre o qual teve suas bases de elaboração enquanto política pública, visando o alcance do direito à moradia.

Entende-se, dessa forma, que a efetivação do direito à moradia incorpora além do bem imóvel, o acesso também a um conjunto de direitos sociais e de urbanidade que estão diretamente conectados com o acesso à cidade e aos seus 
recursos, ou seja, o direito à cidade. Nesse sentido, o direito à cidade, como corrobora Lefebvre (2001), constitui-se como o direito à vida urbana.

$\mathrm{O}$ direito à cidade opõe-se ao ideal da cidade mercadoria que intensifica os processos de segregação e exclusão socioespacial, contribuindo para o aprofundamento das desigualdades sociais das populações mais vulneráveis.

No Residencial Macapaba, para a materialização da política habitacional e para o atendimento das funções sociais da cidade, foram planejados diversos equipamentos públicos, bem como áreas para fomentar o dinamismo econômico com a geração de postos de trabalho, conforme demonstrado no item 2.1.

A realidade do conjunto em termos de equipamentos públicos pode ser retratada da seguinte forma: efetivamente construídos consta, atualmente, apenas 01 (uma) escola de ensino médio, 01 (uma) escola de ensino fundamental e 01 (um) centro esportivo destinado para a realização de atividades recreativas e de lazer com os moradores. Há previsão para a instalação de mais duas escolas de educação infantil e outra de ensino fundamental, mas cujas obras não foram iniciadas.

Nesse aspecto, em relação ao serviço educacional, embora já tenham sido entregues no ano de 2017 dois equipamentos públicos, há uma deficiência na prestação desses serviços, pois não têm sido capazes de atender a demanda dos novos moradores. Tal fato é agravado em decorrência das escolas nos bairros ao entorno também não apresentarem capacidade para o ingresso de novos alunos. Consequentemente, o acesso à educação desses moradores, um direito social, vem sendo comprometido, afetando inevitavelmente a integralidade do direito à moradia na sua perspectiva de alcance da cidadania, para o qual a educação é fundamental.

Outro equipamento público com obra não iniciada refere-se à Unidade Básica de Saúde (UBS), considerada importantíssima para garantir a essas populações o acesso a serviços básicos de saúde, principalmente, devido à carência destes também nas áreas adjacentes. Em todo o bairro, há apenas uma UBS e os dois hospitais do município ficam localizados na Zona Sul da cidade, com uma média de mais de $20 \mathrm{~km}$ de distância. Devido à distância do conjunto em relação a esses equipamentos, muitos moradores acabam não tendo acesso aos serviços, impactando negativamente no alcance do direito à moradia no atendimento dessas necessidades primordiais.

Há ainda os equipamentos públicos funcionando em locais improvisados, como é o caso do terminal rodoviário e do Centro Integrado de Bombeiro e Policiamento Comunitário (CBPM). Em relação ao primeiro, utiliza o espaço da quadra comunitária 07 como ponto de apoio para os funcionários da empresa, e a rua como o ponto de parada principal do terminal. Não há, dessa forma, nenhum tipo de cobertura adequada para proteger os moradores do forte sol ou das chuvas. 
Nesse caso, não há dúvida, de que está sendo prejudicado o acesso a um transporte público de qualidade, também outro direito social. Sem o funcionamento do terminal rodoviário, a estrutura e a oferta do serviço de transporte coletivo no conjunto tornam-se ainda mais precárias e deficientes, comprometendo, dessa maneira, não somente o direito à moradia como também a realização do direito à cidade, já que é por meio desse meio de locomoção que a maioria da população do conjunto acessa os serviços e os equipamentos públicos urbanos.

O Centro Integrado de Bombeiro e Policiamento Comunitário (CBPM), que substituiu no projeto inicial o centro de policiamento comunitário, por sua vez, funciona, na quadra comunitária 04, realizando até o presente momento, apenas o serviço de policiamento, em que são disponibilizados uma viatura e um agente policial durante o dia para o registro das ocorrências. Trata-se, porém, de um serviço que não está conseguindo atender às necessidades dos moradores, principalmente, com aumento dos índices de violência ocorridos no habitacional.

Nesse aspecto, em relação à garantia da segurança no conjunto, há outra deficiência apontada, pois também não apresenta um serviço adequado capaz de garantir o bem-estar dessas populações, interferindo, diretamente no uso que os moradores fazem do espaço urbano e também no seu direito de ir e vir no conjunto. A segurança, assim, é fundamental tanto para efetivação do direito à moradia, como a proteção do bem imóvel, quanto para o uso que as pessoas fazem do espaço público.

Em relação às áreas comerciais, planejadas para funcionar como entreposto comercial com a construção de boxes padronizados e instalações de diversos tipos de estabelecimentos comerciais, e com isso fomentar o desenvolvimento local e a geração de postos de trabalhos formais, está sendo ocupada com barracas improvisadas, miniboxes em contêineres e outros diversos serviços informais, como a instalação de ponto de mototáxi, oficinas, lavagem de carro e outros.

Mais uma vez, o atendimento da função social da cidade no acesso ao trabalho não se concretiza no sentindo em que, esses espaços ocupados de maneira informal, e mesmo tendo se tornado um meio de sustento para essas famílias, não dão a esses indivíduos o acesso às garantias do trabalhador formal, prerrogativas fundamentais para a segurança econômica. E com isso, o direito à moradia, na perspectiva em que é abordada nesta análise e mais ainda o direito à cidade, para o qual o acesso ao trabalho é fundamental, não podem ser efetivados em sentindo pleno.

De maneira geral, a análise demonstra que o direito à moradia, como já discutido anteriormente, é compreendido como além da aquisição do bem imóvel, mas também articulado com um conjunto de direitos sociais, implicando 
consequentemente no direito à cidade, não tem sido plenamente efetivado em se tratando dos moradores do Residencial Macapaba.

$\mathrm{E}$ isso, inevitavelmente, gera implicações na relação que esses indivíduos estabelecem com a cidade e seus recursos, e, por conseguinte, afeta no alcance de uma melhor qualidade de vida urbana, contribuindo para a ampliação da desigualdade social e a exclusão socioespacial que já estigmatiza as populações de baixa renda.

\section{CONCLUSÕES}

O projeto do habitacional Residencial Macapaba visava articular o direito à moradia na sua inter-relação com o direito à cidade a partir da perspectiva do atendimento das funções sociais de cidade, principalmente, em relação à moradia, ao transporte e aos serviços públicos (educação, saúde e segurança) e ao trabalho. No entanto, a realidade do conjunto tem contrastado significativamente com esse ideal de cidade em que foi formulado.

Decorridos, praticamente cinco anos após a finalização da Fase I (2014), e dois anos da Fase II (2017), apenas foram entregues à população as unidades habitacionais, com os serviços de infraestrutura e alguns equipamentos públicos.

Porém, a maior parte dos serviços, que possam de fato atender as funções sociais de cidade, ainda são obras que permanecem no imaginário dos moradores quando não realizados de maneira precária, a exemplo dos serviços de segurança e de transporte.

Sabe-se que todo planejamento governamental fica suscetível a reformulações, a adequações e a imprevistos. No caso do Residencial Macapaba, a demora na implantação dos equipamentos públicos cuja responsabilidade é do governo estadual, tem sido justificada pela crise financeira pela qual passa o país.

Não há dúvidas que os novos moradores estão sendo extremamente prejudicados diante do quadro de situação em que estão expostos. Pois o direito à moradia deve ser compreendido em sua noção mais ampla, garantindo não só o acesso à casa própria, mas também o acesso a um conjunto de direitos sociais que possam de fato promover a melhoria da qualidade de vida dessas populações, estando ligado, portanto, inexoravelmente com o direito à cidade, e com isso combater os processos de exclusão socioespacial, aos quais são submetidas as populações mais vulneráveis, diante do contexto da cidade mercadoria da sociedade capitalista.

Dessa maneira, a implementação do direito à moradia, no caso observado do Residencial Macapaba, vem sendo reduzida à entrega da unidade habitacional 
e de alguns poucos serviços, não atendendo, portanto, a sua função social de cidade, e nem tão pouco do direito à cidade.

Faz-se necessário e urgente que seja garantida a esses moradores a efetivação do direito à moradia na sua inter-relação com o direito à cidade. E, dessa maneira, não se comprometa significativamente os alcances da política habitacional no cenário do município de Macapá, no qual a população, principalmente a de menor renda, assim como no Brasil, em geral, é a que mais sofre mediante a transformação da moradia em ativo financeiro, e com isso, levando a sua exclusão no acesso às melhores habitações na cidade formal.

\section{REFERÊNCIAS}

ALVAREZ, I. P. A segregação como conteúdo na produção do espaço urbano. In: VASCONCELOS, P. de A.; CÔRREA, R. L.; PINTAUDI, S. M. (org.). Cidade contemporânea: segregação socioespacial. São Paulo: Contexto, 2016. p. 39-60.

BRASIL. Ministério das Cidades. Sistema Nacional de Saneamento Ambiental.

Sistema Nacional de Informações sobre Saneamento: diagnóstico dos serviços de água e esgoto - 2014. Brasília, DF: SNSA/MCIDADES, 2016 a. 212 p. Disponível em: http://www.snis.gov.br/diagnostico-agua-e-esgotos/ diagnostico-ae-2014. Acesso em: 19 fev. 2016.

BRASIL. Ministério das Cidades. Portaria Interministerial no 99, de 30 de março de 2016. Dispõe sobre as operações com recursos transferidos ao Fundo de Desenvolvimento Social (FDS), contratadas no âmbito do Programa Nacional de Habitação Urbana(PNHU), integrante do Programa Minha Casa, Minha Vida (PMCMV), para os fins que especifica. Diário Oficial da União, Brasília, DF, p. 52, 31 mar. 2016b.

CARDOSO, A. L. Política Habitacional no Brasil: balanço e perspectiva. Observatório das Metrópoles, Observatório das Metrópoles, Rio de Janeiro, 2008. Seleçao Artigos Científicos. Disponível em: http://www. observatoriodasmetropoles.ufrj.br/download/adauto_polhab_brasil.pdf 2008. Acesso em: 12 mar. 2017.

CARLOS, A. F. A privação do urbano e o "direito à cidade" em Henri Lefebre. In: CARLOS, A. F. A.; ALVES, G.; PADUA, R. F. (org.). Justiça espacial e o direito à cidade. São Paulo: Contexto, 2017. p. 33-62.

CASTELLS, M. A questão urbana. Tradução: Arlene Caetano. Rio de Janeiro: Paz e Terra, 1983. 590p. 
FUNDAÇÃO JOÃO PINHEIRO. Centro de Estatística e Informações. Déficit habitacional, 2013-2014. Belo Horizonte: FJP, 2016. 92p.

GARCIA, R. S. da L. A análise dos novos empreendimentos habitacionais na cidade de Macapá, no periodo de 2000 a 2012: estudo de caso dos conjuntos habitacionais Macapaba e Parque Felicitá. 2014. 93 f. Trabalho de Conclusão de Curso (Bacharelado em Arquitetura e Urbanismo) - Faculdade de Arquitetura e Urbanismo, Universidade Federal do Amapá, Macapá, 2014.

INSTITUTO BRASILEIRO DE GEOGRAFIA E ESTATÍSTICA. Censo Demográfico. Rio de Janeiro: IBGE, 2000.

LEFEBVRE, H. O direito à cidade. Tradução: Rubens Eduardo Farias. São Paulo: Centauro, 2001. 143p.

MARICATO, E. Metropóle, legislação e desigualdade. Estudos Avançados, São Paulo, v. 17, n. 48, p. 151-166, ago. 2003. Disponível em: www.scielo.br/scielo. php?script=sci_arttext\&pid=S0103-40142003000200013. Acesso em: 05 fev. 2017.

OLIVEIRA, J. A. P. de. Desafios do planejamento em políticas públicas: diferentes visões e práticas. RAP, Rio de Janeiro, v. 40, p. 273-288, mar./abr. 2006. Disponível em: http://scielo.br/pdf/rap/v40n2/v40n2a06.pdf. Acesso em: 04 mar. 2017.

RODRIGUES, A. M. Desigualdades socioespaciais: A luta pelo direito à cidade. Cidades, Rio Claro, v. 4, n. 6, p. 73-88, dez. 2007. Disponível em: http:// revista.fct.unesp.br/index.php/revistacidades/article/viewFile/571/602. Acesso em: 16 mar. 2017.

RODRIGUES, A. M. Loteamentos murados e condomínios fechados: propriedade fundiária urbana e segregação socioespacial. In: VASCONCELOS, P. de A.; CÔRREA, R. L.; PINTAUDI, S. M. (org.). Cidade Contemporânea: segregação socioespacial. São Paulo: Contexto, 2016.

ROLNIK, R. Guerra dos lugares: a colonização da terra e da moradia na era das finanças. São Paulo: Boitempo, 2015. 423p.

SEINF. Secretaria Estadual de Infraestrutura. Relatório de Diagnóstico de Demanda Macapaba: fase I. Macapá: SEINF, 2012.

SEINF. Secretaria Estadual de Infraestrutura. Plano de desenvolvimento socioterritorial, empreendimento - residencial Cidade Macapaba Fase I Programa Minha Casa Minha Vida. Macapá: SEINF, 2016. 
SILVA, E. C. da. A urbanização em Macapá após a criação do Estado do Amapá: expansão urbana e desigualdade socioespacial. Ciência Geográfica, Bauru, n. XXI, v. XXI, p. 428-441, jan./dez. 2017. Disponível em: http:www.agbbauru. or/publicações/revista/anoXXI_2/agbxxi2versaointernet/RevistaAGBxxi2-12. pdf. Acesso em: 22 nov. 2017.

SPOSATI, A. Desafios para fazer avançar a política de assistência social no Brasil. Revista Serviço Social e Sociedade, São Paulo, n. 68, ano XXII, p. 5483, nov. 2001.

TOSTES, J. A. Plano Diretor Urbano de 1990. José Alberto Tostes, Macapá, 2012. Disponível em: https://josealbertostes.blogspot.com.br/2012/06/planodiretor-urbano-de-1990.html. Acesso em: 22 jan. 2018.

TOSTES, J. A.; LUZ, R. S. Planejamento urbano na cidade de Macapá: análise do projeto habitacional Macapaba. In: ENCONTRO DA ASSOCIAÇÃO NACIONAL DE PESQUISA E PÓS-GRADUAÇÃO EM ARQUITETURA E URBANISMO ARQUITETURA, CIDADE E PROJETO: UMA CONSTRUÇÃO COLETIVA, 3., 2014, São Paulo. Anais [...]. São Paulo: Mackenzie, 2014. Disponível em: http://www.ufpe.br/ppgdh/ images/ documentos/Idmora_cidade5.pdf. Acesso em: 22 mar.2017.

VILAÇA, A. P. de O; LA MORA, L. de. Habitabilidades e lutas pelo direito a moradia. In: CONFERÊNCIA LATINO-AMERICANA DE CONSTRUÇÃO SUSTENTÁVEL; ENCONTRO NACIONAL DE TECNOLOGIA DE AMBIENTECONSTRUÍDO, 1.;10., 2004,São Paulo. Anais [...].São Paulo:Unicamp, 2004. Disponível em: ftp:///10017719.eng.ufff.br/Public/AnaisEventosCientificos/ ENTAC_2004/trabalhos/PAP1002d.pdf. Acesso em: 21 mar. 2017. 